Original Article

\title{
Effect of aluminum chloride against changes of the histological structure of the cerebral cortex of mice (swiss webster)
}

\author{
Yulia Irnidayanti* and Risa Eno Aprilyanti \\ Research group of Biology, Faculty of Mathematics and Natural Sciences, Jakarta State University, Jakarta, Indonesia
}

Abstract

The toxicity of metal to living organisms, including human beings, was discovered a long time ago. In the present time, aluminum exposure is widely used for wrapping food to keep it taste and smell. However it will affect to human health security, specially the brain. This study aimed to investigate the changes of histological Structure on the cerebral cortex caused by aluminum chloride. The mice were injected intraperitoneally with $\mathrm{AlCl} \mathrm{H}_{3} 200 \mathrm{mg} / \mathrm{kg}$ body weight, once every 3 days, totalizing 10 administrations. Control only was administration distilled water. Histological observations were carried out using the paraffin method. The results of this study show that aluminum chloride cause disorganization of the laminated cerebral cortex, vacuolization, karyolysis, congestion, and hemorrhage. The mice of one and two-months of age group were more susceptible to aluminum chloride than the mice of the three-months of age group. This research can apply for an assessment of the exposure risk to heavy metal. Increasing Al contamination can occur naturally or by anthropogenic activities. The accumulation of the heavy metal in the organism can occur by biomagnification, by which heavy metal is passed from one trophic level to the next within a food web. Therefore communities that live in urban areas potentially exposed to metals aluminum and should be more concerned related to understanding health risks. Further studies are needed to examine the above matters. We recommend calculating the Provisional Tolerable Weekly Intake of aluminum and implication on local people.

Keywords:aluminum, cerebral cortex, disorganization, lamination, susceptible.

Received: 6 January 2021 Revised: 29 March 2021 Accepted: 2 April 2021

\section{Introduction}

Aluminum $(\mathrm{Al})$ remains a very interesting research topic due to equivocal and relatively unknown toxic action. Jakarta as the city center is very polluted, which the problem of water is a big problem. The most of drinking water in regions of the Jakarta center was treated with add both aluminum sulfate and aluminum chloride. Water quality in urban settings has important implications for human health. It reported that an interrelationship between Alzheimer's symptoms and the presence of $\mathrm{Al}$ and fluoride in the drinking water (Ge et al., 2019). Al also presented in cans used for beverages such as colas and fruit drinks, and also found in medications, deodorants. Al element can reach systematic circulation via different routes such as dermal absorption, ingestion, and intramuscular injection (Laabbar et al., 2014).

In everyday life, human beings get exposed to $\mathrm{Al}$ through cooking utensils, food antacids, and deodorants. there have been many reports that the element is detrimental when it enters the body (Tahari et al., 2016). Most aluminum ingested (approximately 95\%) is excreted from the body in the form of feces. However, the remaining $5 \%$ remains in the blood circulation and can accumulate in almost any organ of the human body (Chappard et al., 2016). The remaining 5\% of aluminum in the blood was distributed approximately $80 \% \mathrm{Al}$ was bonded with transferrin, 10\% Al was bounded with

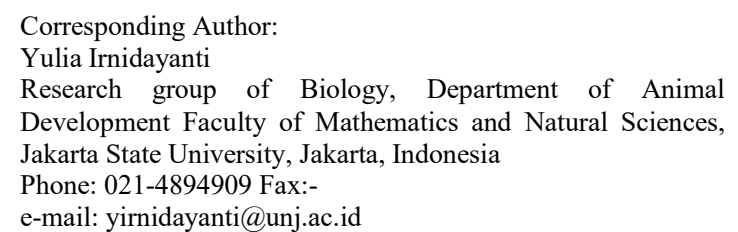

albumin, and $10 \% \mathrm{Al}$ was bonded with other proteins. The distribution of $\mathrm{Al}$ in the brain is about $0.02 \%$, and this value is lower than the distribution in the other tissue. $\mathrm{Al}$ ion charge is approximately similar in size as $\mathrm{Fe}^{3+}$ and can bind transferrin, iron transport protein, and easily circulates throughout the body. Al can penetrate the blood-brain barrier, which caused accumulate in the brain tissues, so induce damage to neurobehavioral reflexes, spatial learning, and memory of offspring ( $\mathrm{Ge}$ et al., 2019). It seems that the brain is the main target of the damage caused by aluminum.

$\mathrm{Al}$ as noxious environmental pollutants can inter-fere with the functions of the brain neurons (Kinawy, 2019), can induce the formation of reactive oxygen species (ROS), and cause interference in nerve cells. It reported that Al significantly enhanced neuronal lipoperoxidation damage. It has a serious bearing on the functional and structural development of the central nervous system, resulting in massive neurodegeneration, deprival of neuron integrity as histological evidence caused by high exposure of Al (Kaur et al., 2009). The capability of Al penetrates the placenta for reach blood circulation, and across the blood-brain barrier of fetal was due to fluoride element. Al always bonds with the other element and promotes oxidative stress, inhibiting the ctivities of the antioxidant enzyme, altering brain neurochemistry, and oxidatively damaging brain DNA, neurons were shrunken darkly stained, and irregular shaped. (Kinawy, 2019).

Kaizer et al (2005) reported that the activation of Acetylcholinesterase (AChE) by $\mathrm{Al}$ exposure can cause pathogenesis of Alzheimer's disease. The brain development disorder is the main progenitor in several 
neurodegenerative disorders such as Parkinson's disease and Alzheimer's disease (Brown et al., 2005). Based on the information from several studies that heavy metals like Al can affect brain development, especially the cerebral cortex. This organ is also participating in Long Term Potentiation (LTP) memory, an essential process involved in learning and memory. Therefore, this research is very important, because the cerebral cortex is the main organ in the process of memory and is also related to the level of intelligence. Interestingly, the synergism of $\mathrm{Al}$ with other metals potentially in enhancing neurotoxicity effects. The purpose of this research is to determine disorders of the cerebral cortex caused by $\mathrm{Al}$ exposure. The observations will be made of the changes in the histological structure of the cerebral cortex using a male mouse model at one month, 2 months, and 3 months of aged.

\section{Methods}

\section{Animal Sample}

The male mice Swiss Webster was used in these experiments. All the mice were derived from the laboratory animal house at the National Agency of Drug and Food Control, Jakarta, and acclimation was carried out in a laboratory at Indonesian University for one week. There were three treatment groups, of one month, two months, and three months of aged. Five males were kept in each cage, with bodyweight ranging from 23.5 to 29.5 g. The animals were reared at temperatures of between $23^{\circ} \mathrm{C}$ and $27^{\circ} \mathrm{C}$, at $83 \%$ humidity. Food and water were given ad libitum (Rugh, 1968). All animal procedures were approved by the Institutional Ethical Committee of Indonesia University, Indonesia (Protocol number KET496/UN2.F1/ETIK/PPM.00.02/2019).

\section{Experimental Design}

The aluminum chloride $\left(\mathrm{AlCl}_{3}\right)$ used (CAS-No:778413-6) was produced by Merck, Germany, and was diluted with sterilized distilled water. The mice were divided into four groups $(\mathrm{n}=5)$ by randomly. The Altreated group at one month, two months, and three months of aged were administered $200 \mathrm{mg} / \mathrm{kg} \mathrm{BW} \mathrm{Al}$ solution (Guo et al. 2001). The intraperitoneal injection of Al carried out on $1^{\text {st }}, 3^{\text {rd }}, 6^{\text {th }}, 9$ th $, 12^{\text {th }}, 15^{\text {th }}, 18^{\text {th }}, 21^{\text {th }}$, $24^{\text {th }}$, and $27^{\text {th }}$. The control mice were only given sterile distilled water with the same dose. The mice were weighed to monitor their body weight.

\section{Tissue Preparation}

The mice were killed by cervical dislocation and brains were removed and isolated under a stereomicroscope. Histological observations were carried out using the paraffin method (Conn and Darrow, 1960). The brains were fixed in a buffer neutral formalin $10 \%$ until the final analysis. Gradual dehydration in alcohol with increasing concentrations $(60 \%, 70 \%, 80 \%, 90 \%$, and $100 \%$ ) was performed. Purification was done by a solution of alcohol-xylol and xylol, and paraffin infiltration was carried out in an oven at a temperature between $57^{\circ} \mathrm{C}$ and $60{ }^{\circ} \mathrm{C}$. Hematoxylin-eosin staining was used in this research. The prepared brain tissue was sliced to $5 \mu \mathrm{m}$ with a rotary microtome. Finally, the sample on the slide was covered with coverglass after application of a drop of entellan, for observation under the microscope. Analysis of the histological structure of the cerebral cortex was done using a light microscope. The cerebral cortex consisting of six layers: the molecular zone, the cortical plate, the subplate, the intermediate zone, the subventricular zone, and the ventricular zone. The observation was also done on the morphology of pyramid-shaped nerve cells and the granular neuron cells, an arrangement pattern of granular neuron cells, shape and location of the granular neuron cells nucleus, congestion, and hemorrhage in the layers of the cerebral cortex. There is no statistical analysis and all images of the histological structure of the cerebral cortex layers were compared than controls.

\section{Results}

The histological structure of the cerebral cortex consists of six layers: (1) the molecular zone (MZ), containing some neurons; (2) the cortical plate (CP), a relatively thin layer filled with neurons;(3) the subplate (SP), composed of pyramid-shaped nerve cells of medium size, (4) the intermediate zone (IZ), composed of irregularly shaped neurons; (5) the subventricular zone (SVZ), composed of pyramid-shaped nerve cells, and (6) the ventricular zone (VZ), composed of two types small polymorphic nerve cells, round and spindle-shaped (fusiform). The VZ layer is also known as a the multiform layer, as it contains two types of cells.

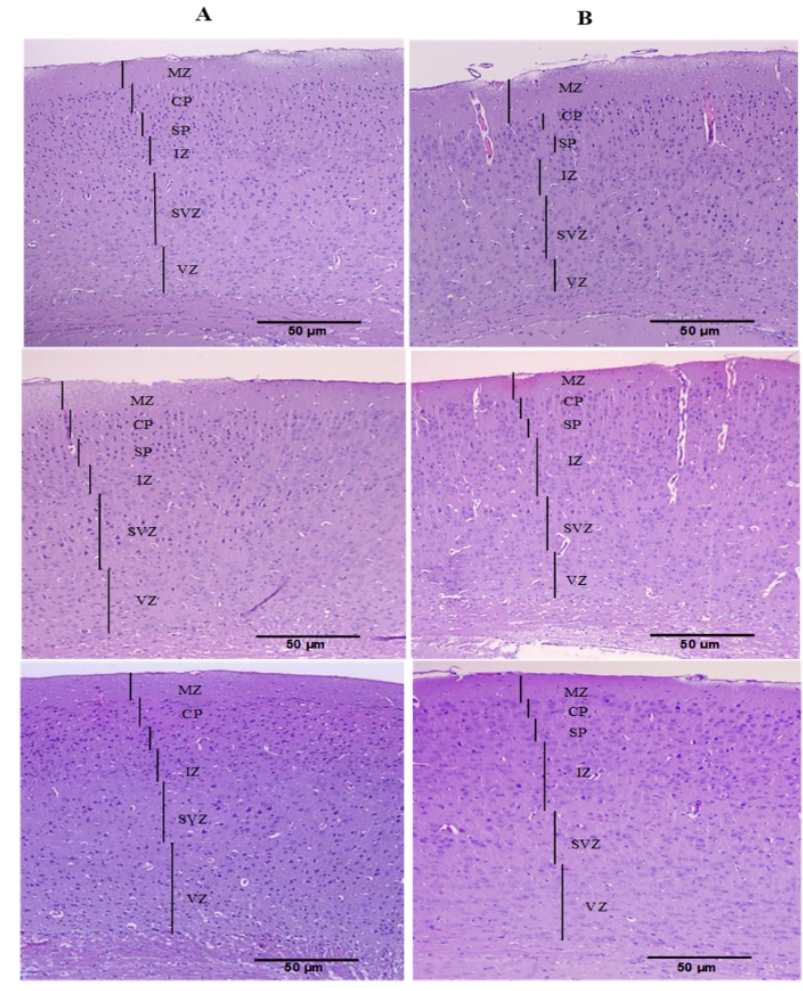

Figure 1. Cross section of cerebral cortex on male mice without (A) and with Al (B) administration at a dosage of $200 \mathrm{mg} / \mathrm{BW}(100 \mathrm{x}, \mathrm{HE})$. From top to bottom: one month of aged, two months of aged and three months of aged 
In this study, the histological structure of the cerebral cortex of mice at Al-treatment group one month of aged, Al-treatment group two months of aged, and Altreatment group three months of aged that were given $\mathrm{Al}$ at doses of $200 \mathrm{mg} / \mathrm{kg} \mathrm{BW}$ also consists of the six layers detailed likes above. The MZ on the cerebral cortex of mice at Al-treatment group one month of aged was relatively thicker (Fig. 1B) than the $\mathrm{MZ}$ on the cerebral cortex of the control (Fig. 1A), while the MZ on the cerebral cortex of mice at Al-treatment group two months of aged and three months of aged do not differ than the MZ on the cerebral cortex of the control in thickness. The main constituent of the $\mathrm{MZ}$ is dense connective tissue (Fig. 1).

The CP and SP on the cerebral cortex of the mice at the Al-treatment group one month of aged were relatively thinner than the $\mathrm{CP}$ and $\mathrm{SP} \mathrm{n}$ the cerebral cortex of mice the control (Figs. 2A \& 2B, the first row) . While the $\mathrm{CP}$ and SP on the cerebral cortex of mice at the Al-treatment group two months and three months of aged were relatively the same as the $\mathrm{CP}$ and $\mathrm{SP}$ on the cerebral cortex of mice the control (Figs. $2 \mathrm{~A} \& 2 \mathrm{~B}$, the second $\&$ the third row). The granular neuron cells in the $\mathrm{CP}$ in the cerebral cortex of the Al-treatment group one month of aged were relatively more numerous than the cerebral cortex of the control group.
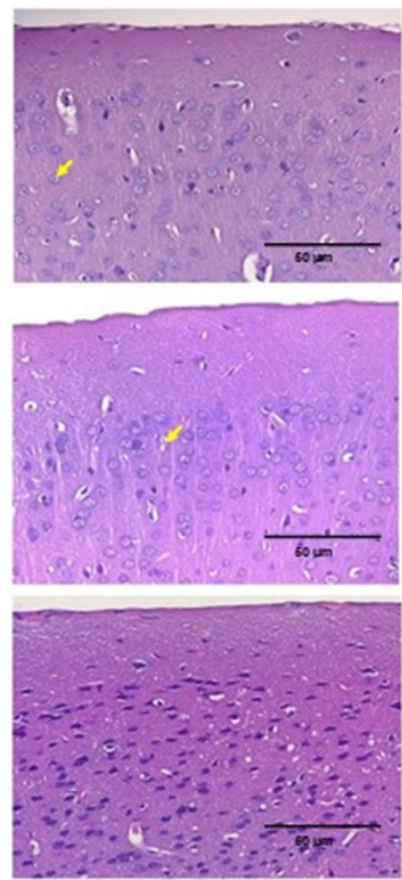
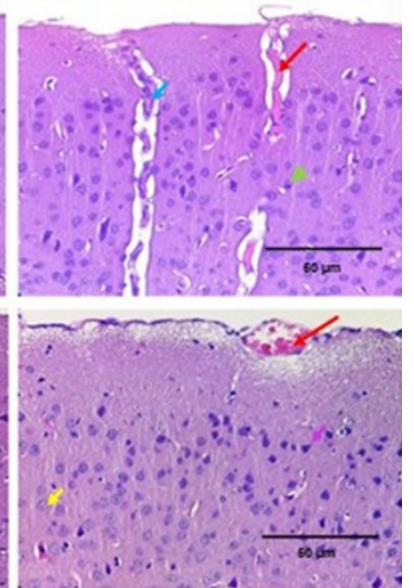

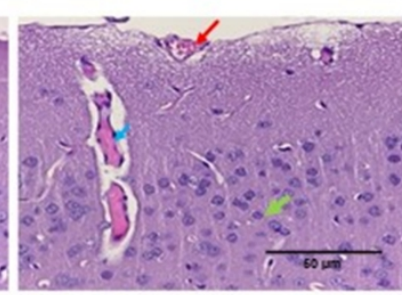

Figure 2. Microscopy observation of molecular zone (MZ), cortical plate (CP) and Sub Plate (SP) of cerebral cortex on male mice without (A) and with $\mathrm{Al}(\mathrm{B})$ administration at a dosage of $200 \mathrm{mg} / \mathrm{BW}(400 \mathrm{x}$, $\mathrm{HE}$ ). From the top row down are mice one month of age, two months of age, and three months age. Pynoksis (green arrow), granular neuron cells were seen with large nuclei,prominent nucleolus and little cytoplasm (yellow arrow), congestion (red arrow), hemorrhage (blue arrow), pyknosis/shrunken pyramidal cell (pink arrow). From top to bottom: one month of aged, two months of aged and three months of aged.

The granular neuron cells have dominated in CP and SP of the cerebral cortex of the Al-treatment group one month and two months of age. In control mice, the granular neuron cells have spherical or pyramidal perikaryon with large nuclei, and also arranged in a regular pattern or arranged closely (Fig. 2B, the second row). The pyramidal neurons exhibit general characteristics, which was the shape of their nuclei are rounded, clear, large, and centrally located. The administration of $\mathrm{Al}$ affects the arrangement of cells in the CP and SP of the cerebral cortex in the Al-treatment group one month and three months of age, where are some of the granular neurons and small pyramidal cells were undergone shrunken and pycnosis (Fig. 2B, the second and third row). The blood congestion was found on the CP and SP of the cerebral cortex in the Altreatment group one month and two months of aged, and all MZ of the cerebral cortex in the Al-treatment group undergoing hemorrhage.

The IZ consists of smaller portion of the pyramidal cells and the granular neurons cells relatively large in number (Fig. 3A, the first row). The IZ in the cerebral cortex of the Al-treatment group one month of age is relatively different to the control group, where is found granular neuron cells in numerously. Several of the granular neuron cells and pyramidal cells were indicated pycnosis. The pyramidal cells appeared irregular in shape and darkly stained with loss of their processes, others showed marked vacuolization with faintly stained cytoplasm (Fig. 3B, the first row). The IZ of the cerebral cortex at the Al-treatment group three months of age was showed also some pyramidal cells irregular in shape and darkly stained with loss of processes (Fig. 3B). Some granular cells in IZ of the cerebral cortex at the Altreatment group three months of age indicated pycnosis, but relatively there were no differences with control.

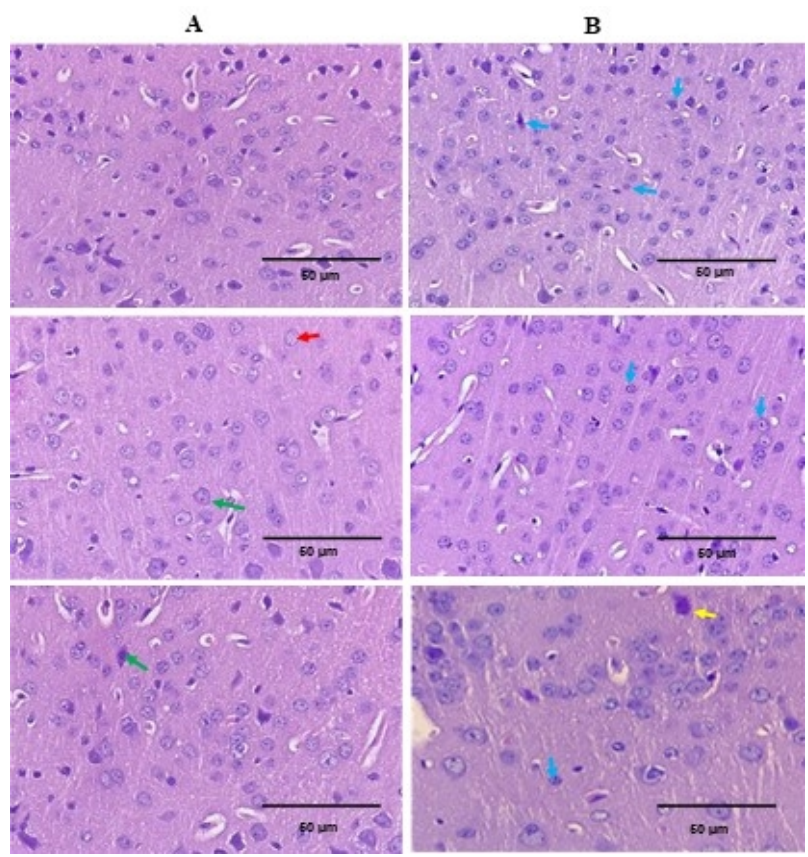

Figure 3. Microscopy observation of molecular intermediate zone (IZ) of cerebral cortex on male mice without (A) and with $\mathrm{Al}$ (B) administration at a dosage of $200 \mathrm{mg} / \mathrm{BW}(400 \mathrm{x}, \mathrm{HE})$. From the top row down are mice one month of age, two months of age, and three months age. Pyramidal cell was Shrunken (yellow arrow), pyramidal cell (green arrow), granular neurons cells was pyknosis (blue arrow), the granular neurons cells (red arrow). From top to bottom: one month of aged, two months of aged and three months of aged 
The subventricular zone (SVZ), is located adjacent to the VZ along the lateral ventricular wall. The SVZ layer in the cerebral cortex of all control group contains many large pyramidal cells, cone-shaped (Fig. 4A). The number of pyramidal cells the SVZ layer (Fig. 4B) in the cerebral cortex of all the Al-treatment group were fewer than their the control group (Fig. 4A). Apparently, the granular neuron cells was dominate SVZ layer of the cerebral cortex on Al-treatment group (Fig. 4B). The granular neuron cells were seen with large nuclei, prominent nucleolus and little cytoplasm, some of the pyramidal cell undergone vacuolization and pycnosis.

A

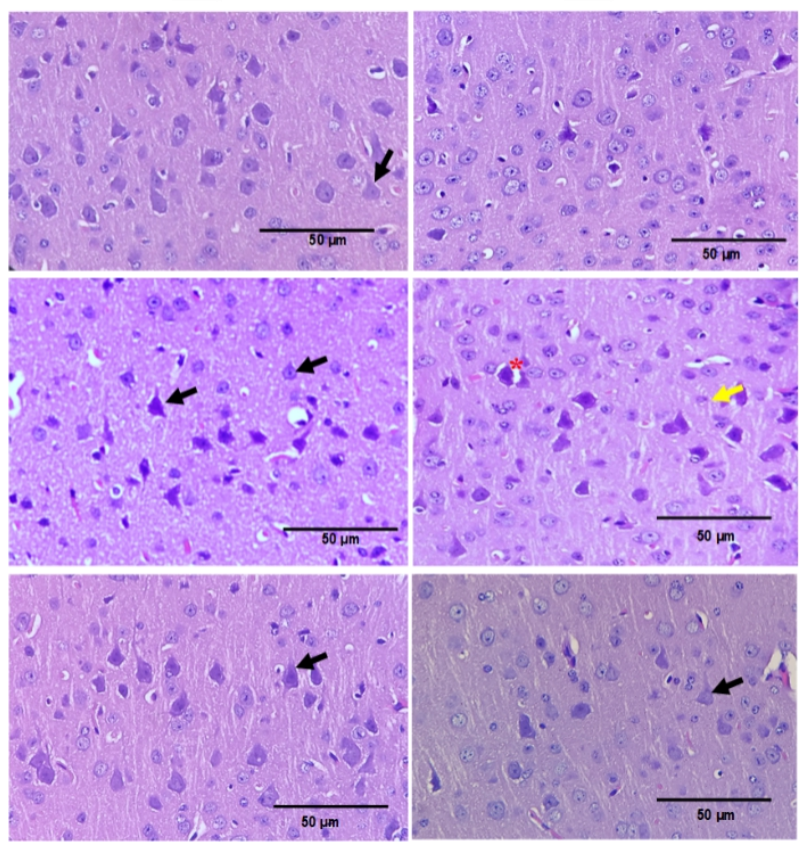

Figure 4. Microscopy observation of subventricular zone (SVZ) of cerebral cortex on male mice without (A) and with $\mathrm{Al}$ (B) administration at a dosage of $200 \mathrm{mg} / \mathrm{BW}(400 \mathrm{x}, \mathrm{HE})$.From the top row down are mice one month of age, two months of age, and three months age. Large pyramidal cell (black arrow), vacuolization of the pyramidal cell $(*)$, pycnosis (yellow arrows). From top to bottom: one month of aged, two months of aged and three months of aged.

The ventricular zone (VZ) lies in the deepest of the cerebral cortex. Neural precursors have been identified in the normal VZ layer, which contains neuroepithelium cells and actively proliferates, and can differentiate into neuroblasts and glial cells. The neuroepithelium is multipotent neural stem cells. The neurons have characteristics of elongated cells with light cytoplasm and contained lax chromatin and one or two nucleoli.

Neuroblast cells in this layer are granular neuron cells, which is actively proliferate and migrate to the layer above, the IZ layer (Kirkcaldie et al. 2012). This study shows that the morphological characteristics of the cells in the VZ layer in all the Al treatment groups do not differ from their control. The characteristics of granular neuron cells in the VZ layer are polymorphic, small, round like a spindle or fusiform in shape (Fig. 5A \& 5B).


Figure 5. Microscopy observation of ventricular zone (VZ) of cerebral cortex on male mice without $(\mathrm{A})$ and with $\mathrm{AlCl} 3(\mathrm{~B})$ administration at a dosage of $200 \mathrm{mg} / \mathrm{BW}(400 \mathrm{x}, \mathrm{HE})$. From the top row down are mice one month of age, two months of age, and three months age. Vacuolization of pyramidal cell (red arrow). From top to bottom: one month of aged, two months of aged and three months of aged.

\section{Discussion}

Exposure to Al has become unavoidable due to its increased use in different industries, and extensive use in our daily life, it has now become a universal health problem (Shaw, 2018). The effect of $\mathrm{Al}$ is probably due to direct interaction with cellular components, which can affect the physical state of membranes. Al has the ability to bind membranes and displace membrane-bound iron, which causes a greater rearrangement of the membrane phospholipids. On the other hand, it suggests that the effect of $\mathrm{Al}$ on the brain is related to an accumulation of $\mathrm{Al}$ in the brain membranes. The accumulation of $\mathrm{Al}$ in the brain associated with many human pathological conditions, especially neurodegenerative diseases.

In this study, that $\mathrm{Al}$ causes a changed layer in the $\mathrm{MZ}, \mathrm{CP}$ and SP on the cerebral cortex of mice at the Altreatment group one month of age (Fig. 1B), if it compare than their control (Fig. 1A). This data supported by various authors, that disorganization in the layers of cerebral cortex result from the increased amount of ROS (reaction oxygen species). The presence of ROS can demage membranes, lipids and proteins, thus affecting the histoarchitecture of layers in the cerebral (Bhalla dan Dhawan, 2009). The brain is an organ sensitive to peroxide damage. A high proportion of polyunsaturated fatty acids (PUFAs) content, low levels of natural antioxidants, and high oxygen consumption are characteristic of brain membrane. These characteristics are especially sensitive to peroxide and ROS (Azib et al., 2019). The peroxidation of the brain membrane is one of the most important mechanisms. Al exists as cation $\left(\mathrm{Al}^{3+}\right)$, cannot initiate peroxidation due to 
not a transition metal. The presence of Al contributes and can effectively aggravate $\mathrm{Fe}$ initiated lipid peroxidation. In the Fenton reaction, iron is a redox metal, when it transforms from $\mathrm{Fe}^{2+}$ to $\mathrm{Fe}^{3+}$, generates the hydroxyl radical. This radical is one of the most reactive free radical species, can attack the membrane phospholipids and initiates their peroxidation.

The Peroxidative action of $\mathrm{Fe}$ causes binding of $\mathrm{Al}$ directly to the membrane. It was caused Al possesses a high affinity to phosphate groups on the membrane. The rearrangements of membrane lipids facilitate the $\mathrm{Fe}$ attack (Nehru and Anand, 2005). In the present study, aluminium maybe altering the cellular redox state by inhibiting the enzymes involved in antioxidant defense. As brain is an organ susceptible to peroxide damage, even more in mice that the development of the brain occurs in the postnatal period, then pro-oxidant effects of $\mathrm{Al}$ maybe damage the neuronal membrane by altering the physical properties of the membrane, interfering with the functioning of voltage-activated ionic channels, or altering the secretion of neurotransmitters. Therefore, damage of the brain membrane by $\mathrm{Al}$ causes the $\mathrm{MZ}$ layer on the cerebral cortex of mice at Al-treatment group one month of aged was relatively thicker than the $\mathrm{MZ}$ on the cerebral cortex of the control. The mice of one and two-months of aged group were more susceptible to aluminum chloride than the mice of the three-months of aged group.

ROS can also cause changes in membrane permeability in blood vessels. Such changes lead to rupture of blood vessels and cause accumulation of blood cells and plasma in the connective-tissue area of the cerebral cortex. Blood is trapped in this layer in the form of tissue haemorrhage (Abu Almaaty et al., 2020). This study was supported by Said and Rabo (2017) that Al can cause hemorrhagic and congestion of blood vessels in the cerebral cortex. The research was also supported by Ali et al. (2016) that Al can cause hemorrhagic with edema in the meninges, which is related to congestion of blood vessels in the cerebral cortex. In this study that congestion and haemorrhage on the cerebral cortex of mice at the Al-treatment group one month, two months and three months of aged, it is suspected that the accumulation of $\mathrm{Al}$ affects the permeability of blood vessels, changing them from being semipermeable to permeable against Al. Changes in permeability of the endothelial membrane of blood cells cause membrane vasodilation and increased local blood flow. This condition in turn leads to rupture of blood vessels. The presence of hemorrhage and congestion may be also the cause of disrupted nutrient supply that affects the death of pyramidal cells.

The administration of $\mathrm{Al}$ affects the arrangement of cells in the CP and SP of the cerebral cortex in the Altreatment group three months of aged, where are some of the granular neurons and small pyramidal cells were undergone shrunken and pyknosis, consistent with the previous report ( Liaquat et al., 2019). In control mice nuclear membrane was clear and the granular neuron cells were arranged closely and had circular shape, whereas in $\mathrm{Al}$ injected rats nuclear membrane was indistinct and neurons had irregular shape
The pyramidal cells may be the target of ROS and can trigger cell death (Rafati et al. 2015). The Al in cells will be stored in vacuoles of pyramidal cells, so as not to disturb the core of nerve cells, but if the accumulation of $\mathrm{Al}$ exceeds the storage capacity of the cell, the vacuole breaks. The results of this study indicate that the administration of $\mathrm{Al}$ to cerebral cortex can cause the nuclei of granular neuron cells to undergo pyknosis, and undergo karyolysis. Therefore, it is suspected that $\mathrm{Al}$ can cause nerve cells to undergo necrosis due to reduced nutrition and oxygen supply, leading to a reduced density of pyramidal in the Al-treatment group three months of aged. In this research, the excessive $\mathrm{Al}$ given to mice led to neurotoxicity, appearing in the form of shrunken pyramidal cells, reduced numbers of pyramidal cells, with faintly stained cytoplasm indicating detached neuron fibers, irregular in thickness. These brain changes induced by $\mathrm{Al}$ administration were due to oxidative damage, which contributes to disease pathogenesis.

Cytoplasmic vacuolation in Al-treated mice may be due to lipid peroxidation, damage of the cell membranes and membranes of some organelles. The elevation of sodium permeability may be can raise the capacity of the pump to extrude sodium. This condition can cause elevated water content in the cytoplasm of the cell and causing neuronal cell swelling. Cytoplasmic vacuoles could be also resulted from swollen mitochondria, and may be related to neuronal cell shrinkage (Aboelwafa et al., 2020). High Al accumulation can stimulate glial cells to proliferate and bind $\mathrm{Al}$, that can protect granular neuron cells. Glial cells play the initial role in Al toxicity, by binding to $\mathrm{Al}$ to protect nerve cells and maintain nerve cell homeostasis against ROS (Oshiro et al. 2000). Nerve cells are very susceptible to ROS because they have lower glutathione levels than is found in astrocyte cells. This condition causes glial cells to be more resistant to ROS than neuron granular cells. However, the role of neuroglial cells still needs to be investigated. This study show that $\mathrm{Al}$ produce marked histopathological alterations.

The study concluded that exposure to Al resulted in cerebral cortical disorder in male mice as observed in $\mathrm{Al}$ treated group of mice. Histological study of the cerebral cortex revealed that the cerebral cortex layers of the aluminum-treated groups showed a reduction of granular neuron cells and pyramidal cells. Al affects the cerebral cortex of male mice, the granular neuron cells were undergone pycnosis and shrunken, and the pyramidal cells were undergone vacuolization and pycnosis. The study concluded that $\mathrm{Al}$ has a neurotoxic effect on the cerebral cortex of adult male mice.

\section{Ethical approval}

The study was approved by the Ethics Committee of University of Indonesia, Indonesia.

\section{Acknowledgements}

We would like to express our gratitude to Mr. Kanto who helped me to make the histological slide in this 
study. This study was financed by the Directorate General of Higher Education of Indonesia (Grant contract no: 4/SP2H/ DRPM/ LPPM-UNJ/III/2019).

\section{References}

Abu Almaaty, A. H., El-Aziz, A., Yasmin, M., Omar, N. A., Abdeen, A. M., Afifi, H., ... \& Khedr, A. I. (2020). Antioxidant Property of the Egyptian Propolis Extract Versus Aluminum Silicate Intoxication on a Rat's Lung: Histopathological Studies. Molecules, 25(24), 5821.

Aboelwafa, H. R., El-Kott, A. F., Abd-Ella, E. M., \& Yousef, H. N. (2020). The possible neuroprotective effect of silymarin against aluminum chloride-prompted Alzheimer's-like disease in Rats. Brain sciences, 10(9), 628.

Ali, A. A., Ahmed, H. I., \& Zaky, H. S. (2016). Stress as a risk factor in induction and progression of alzheimer's disease: Impact on the possible protection using epigallocatechin-3-gallate and/or diazepam. Ann Clin Toxicol. 2018; 1 (1), 1003.

Azib, L., Debbache-Benaida, N., Da Costa, G., Atmani-Kilani, D., Saidene, N., Ayouni, K., ... \& Atmani, D. (2019). Pistacia lentiscus L. leaves extract and its major phenolic compounds reverse aluminium-induced neurotoxicity in mice. Industrial Crops and Products, 137, 576-584.

Brown, R. C. (2005). Brown, Alan H. Lockwood, Babasaheb R. Sonawane. Neurodegenerative Diseases: An Overview of Environmental Risk Factors. Environ. Health Perspect, $113(9), 1250$.

Bhalla, P., \& Dhawan, D. K. (2009). Protective role of lithium in ameliorating the aluminium-induced oxidative stress and histological changes in rat brain. Cellular and molecular neurobiology, 29(4), 513-521.

Chappard, D., Bizot, P., Mabilleau, G., \& Hubert, L. (2016). Aluminum and bone: Review of new clinical circumstances associated with $\mathrm{Al} 3+$ deposition in the calcified matrix of bone. Morphologie, 100(329), 95-105.

Conn H. J., and Darrow M. A. (1960). Staining Procedures. The William and Wilkins Co, Baltimore, pp146-147

Guo, C. H., Huang, C. J., Chen, S. T., \& Hsu, G. S. W. (2001). Serum and testicular testosterone and nitric oxide products in aluminum-treated mice. Environmental toxicology and pharmacology, 10(1-2), 53-60.

Ge, Q. D., Xie, C., Zhang, H., Tan, Y., Wan, C. W., Wang, W. J., \& Jin, T. X. (2019). Differential expression of miRNAs in the hippocampi of offspring rats exposed to fluorine combined with aluminum during the embryonic stage and into adulthood. Biological trace element research, 189(2), 463477.

Kaizer, R. R., Corrêa, M. C., Spanevello, R. M., Morsch, V. M., Mazzanti, C. M., Gonçalves, J. F., \& Schetinger, M. R. (2005). Acetylcholinesterase activation and enhanced lipid peroxidation after long-term exposure to low levels of aluminum on different mouse brain regions. Journal of inorganic biochemistry, 99(9), 1865-1870.

Kaur, T., Bijarnia, R. K., \& Nehru, B. (2009). Effect of concurrent chronic exposure of fluoride and aluminum on rat brain. Drug and chemical toxicology, 32(3), 215-221.

Kinawy, A. A. (2019). Synergistic oxidative impact of aluminum chloride and sodium fluoride exposure during early stages of brain development in the rat. Environmental Science and Pollution Research, 26(11), 10951-10960.

Kirkcaldie, M. T. K., Watson, C., Paxinos, G., \& Franklin, K. (2012). Straightening out the mouse neocortex. In Australian Neuroscience Society Annual Conference.

Laabbar, W., Elgot, A., Kissani, N., \& Gamrani, H. (2014). Chronic aluminum intoxication in rat induced both serotonin changes in the dorsal raphe nucleus and alteration of glycoprotein secretion in the subcommissural organ: Immunohistochemical study. Neuroscience letters, 577, 72 76.

Liaquat, L., Sadir, S., Batool, Z., Tabassum, S., Shahzad, S., Afzal, A., \& Haider, S. (2019). Acute aluminum chloride toxicity revisited: Study on DNA damage and histopathological, biochemical and neurochemical alterations in rat brain. Life sciences, 217, 202-211.

Nehru, B., \& Anand, P. (2005). Oxidative damage following chronic aluminium exposure in adult and pup rat brains. Journal of Trace Elements in Medicine and Biology, 19(2-3), 203-208.

Oshiro, S., Kawahara, M., Kuroda, Y., Zhang, C., Cai, Y., Kitajima, S. \& Shirao, M. (2000). Glial cells contribute more to iron and aluminum accumulation but are more resistant to oxidative stress than neuronal cells. Biochimica et Biophysica Acta (BBA)-Molecular Basis of Disease, 1502(3), 405-414.

Said, M. M., \& Abd Rabo, M. M. (2017). Neuroprotective effects of eugenol against aluminiuminduced toxicity in the rat brain. Arhiv za higijenu rada i toksikologiju, 68(1), 27-36.

Rafati, A., Yazdani, H., \& Noorafshan, A. (2015). Pioglitazone ameliorates neuron loss in the cortex after aluminumtreatment in rats. Neurology research international, 2015.

Rugh R. (1968). The mouse; its reproduction and development. Burgess Pub. Co.

Shaw CA. 2018. Aluminum as a CNS and immune system toxin across the life span; In Neurotoxicity of Aluminum. Springer. Singapore. 53-83.

Tahari, F. Z., Lablack, M., Hamadouche, N. A., Tahari, Z., \& Aoues, A (2016). Protective effect of Haloxylon salicornicum on hepatic and renal functions of Wistar rats exposed to aluminium. African Journal of Biotechnology, 15(9), 293302. 